\title{
The Materials Career: A Shared Responsibility
}

September is the peak of the season of "back-to-school." One comforting aspect of school is its relative predictability. Students almost always know in advance what they will be studying and with whom, and they are offered more and more control over their study program as time goes on. At the same time, they become increasingly aware of the possible consequences, risks, and rewards of their choices.

Why should the choice be materials? For many, the prospect of a career that can include investigation, discovery, physical sensation, construction, debate, creativity, entrepreneurship, and camaraderie would be most attractive. Some students are able to match their natural affinities with materials-related career plans. For many others, however, the nature and visibility of the potential rewards provide insufficient motivation for students to pursue materials sciencerelated degrees.

Extensive discussion is under way among some members of the U.S. government, within the National Science Board, ${ }^{1}$ and in professional societies about the need for an expanded technological workforce in order to maintain economic competitiveness in the global market. Part of the discussion is motivated by an anticipated lack of competitiveness with nations that are more proactively developing their scientific human capital. Even in view of the goal of absolute, rather than relative, economic development that transcends national borders, the case for investment in scientifically capable people-especially in the physical sciences-is compelling. However, in order to enable the development of this needed technological workforce, much more has to be done by stakeholders to motivate students. Academic materials departments and other departments where materials research takes place definitely have a role to play. Materials science and engineering is at the intersection of many fields where there is a stated need for higher performance materials and a more highly trained materials-conscious workforce. This need should be enthusiastically and cordially articulated in a broad range of classroom settings and demonstrated in less formal situations. Coursework and research programs need to be relevant to the emerging drivers of materials technology, and not just based on a tried-andtrue syllabus.

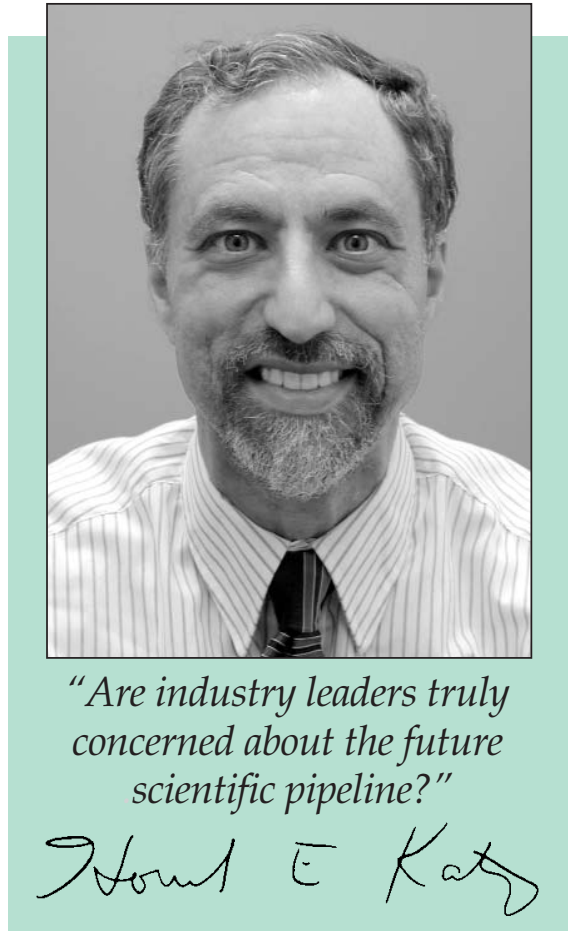

can be fun to watch, but very few of us want to bet our lives on such winner-takeall contests.

Suppose, however, that there is really no business model for industries to sustain a larger, stable workforce in the physical/materials sciences, despite their best intentions. Governments recognize long-term needs for materials researchers in energy, medicine, security, and the environment. If governments are sincere, then their responsible action would be to radically increase their support for the materials science and engineering enterprise through conventional university funding and increased co-investment in industry, the establishment of tenured industrial positions, and major upgrades to national laboratories. Funding needs to be approved independent of unrelated agencies drawing from the same appropriations subcommittee trough. Objections to government "doing industry's job" based on capitalist ideology cannot stand in the way. Investment in technology has to begin with investment in people.

Just as MRS has set up its structure to develop human resources by more strongly empowering committees and actively cultivating volunteer leadership candidates (as have many of our best schools), government research agencies have to take the human resource issue much more seriously. This does not mean supporting only underprivileged candidates at one end and Nobel Prize candidates at the other. As the U.S. election approaches, it is fair to ask which elected officials of the U.S. government take a view beyond the election and which of them emulate those corporate directors whose view, for whatever reasons, extends only to the next quarterly report.

It is also prudent for us in materials research to take as much control of our careers as we can. One way is to retain ownership of our discoveries as they become technological and commercial successes, in cooperation with our supporting institutions. This is how we can maximize our own success and provide the best role models for our returning students.

HOWARD E. KATZ 2004 MRS President

be some measure of security and predictability that transcends stock market fluctuations, or the best and brightest will make other choices. Industry has disregarded fundamental life path considerations in setting up a climate of elimination rather than advancement. Tournaments should set up career paths that would be worth following, as judged by those about to embark on them. There needs to

\section{Reference}

1. National Science Board, "Science and Engineering Indicators 2004," www.nsf. gov/sbe/srs/seind04/start.htm (accessed August 2004). 